\title{
Bridge Abutment Protection against Scouring for Unsteady Flow Conditions
}

\author{
Maryam Khajavi ${ }^{*}$, Seyed Mahmood Kashefipour ${ }^{1}$, Mahmood Shafai Bejestan $^{1}$ \\ ${ }^{1}$ Department of Hydraulic Structures, Faculty of Water and Environmental Engineering, Shahid Chamran University of Ahvaz, Golestan \\ Blvd., 61357-83151, Ahvaz, Khuzestan, Iran \\ *Corresponding author, e-mail: m-khajavi@stu.scu.ac.ir
}

Received: 06 July 2021, Accepted: 09 December 2021, Published online: 16 December 2021

\begin{abstract}
The bridge abutment is one of the main parts of a bridge and significantly contributes to bridge stability. This study experimentally investigated the effect of the unsteadiness characteristics of hydrographs on the scouring phenomenon around the bridge abutment under clear water conditions. The ability of the permeable and impermeable spur dikes and their distances from the abutment at its upstream on the control of scouring around the bridge abutment was also investigated. The experimental observations imply that the effect of unsteady flow on the scouring process is relatively similar to the steady flow conditions. The results showed that the base time of hydrographs, the type of spur dikes, and the distance of spur dikes from the bridge abutment were the dominant parameters among the considered parameters in this study on the scouring process around the abutment. The results also revealed that the impermeable spur dike was able to completely eliminate scouring around the bridge abutment for two distances of $2 \mathrm{~L}$ and $3 \mathrm{~L}$ (where $L$ is the abutment length) for both steady and unsteady flow conditions.
\end{abstract}

Keywords

bridge abutment stability, permeable and non-permeable spur dikes, local scour, unsteady flow conditions

\section{Introduction}

In many places around the world, rivers are the main source of water for drinking in urban and rural sectors as well as for use in agricultural and industrial zones. Rivers also play a major role in receiving wastewater and effluent. Therefore, management and maintenance of rivers are of particular significance to water authorities. Different aspects of rivers such as water pollution, navigation, erosion and sedimentation, river structures, bed and bank protection, and etc., are of interest for researchers.

Bank degradation in rivers causes many problems such as the destruction of river structures, damage of agricultural lands, immigration of river bends, change of river paths, and loss of land ownerships. Generally, most changes in river banks occur in the vicinity of river structures due to the higher velocities of flow, changes of flow velocity directions, and generated horseshoe and different types of vortices. Bridges over rivers are the most common river structures that may cause changes in natural river hydraulic conditions. Bridge piers and abutments reduce the width of the river and may damage the river bed and bank by increasing flow velocity, generating vortices and the separation phenomenon around them.
Hydraulic structures are generally designed based on data collected for steady flow conditions with a maximum discharge. However, this type of design usually overestimates the dimensions of structures that are needed to withstand against scouring and degradation. In the last decade, many researchers have focused on the local scouring around the hydraulic structures for unsteady flow conditions [1-3]. Floods as unsteady flows, which frequently occur in rivers, are specified by hydrographs with different shapes, peak discharges, and base times.

Bridges are extensively used for roads, rails, and pipelines to cross over channels, streams, rivers, and narrow estuaries. Most of the problems created during floods are related to bridges, causing destruction of bridges, blockage of river, or destruction of side walls of bridges [1]. There are a few references in the literature emphasizing the scouring phenomenon around bridge piers under unsteady flow conditions [3].

The bridge abutment is usually built at the intersection of the bridge and the riverbank, and is known as a significant and essential part of the bridge for its stability. Scouring around this structure may lead to destruction of 
the bridge and the river bank. After comprehensive studies by Melville [4] and Ettema [5], the scouring mechanism around the bridge pier was completely clarified, and it was determined that after impacting the flow to the pier, its velocity becomes zero and the pressure gradient increases. In this situation, a downward current or down flow is created; this current is combined with the flow in longitudinal direction, and the horseshoe vortices are generated. The separation phenomenon occurs behind the pier, and the wake vortices are formed. These two types of vortices are the main cause for scouring around the bridge piers [6]. Further studies by Kwan [7], Kandasamy [8], Dongol [9] and other researchers imply that the scouring mechanism around the bridge abutment is highly similar to the pier scouring. The only difference is related to the wall boundary layer, making the scouring phenomenon more complex for abutments than for piers [10]. Furthermore, studies have shown that under similar conditions, the scouring depth values for abutments are less than the corresponding values for piers, which is because of the predominant boundary layer produced by the channel wall [11]. Flow and vortices around the bridge abutment are schematically shown in Fig. 1.

Estimation of the maximum scour depth around the abutment is a key parameter for design of this structure, which is usually performed based on steady flow conditions. Many studies [12-14] have been carried out for the prediction of this parameter.

Different methods are usually applied for bridge abutment and riverbank protection against local scouring and finally destruction in river engineering projects. Riprap, installation of a geotextile layer, and construction of a reinforced concrete layer and a protective retaining wall are some of the direct methods for strengthening river banks

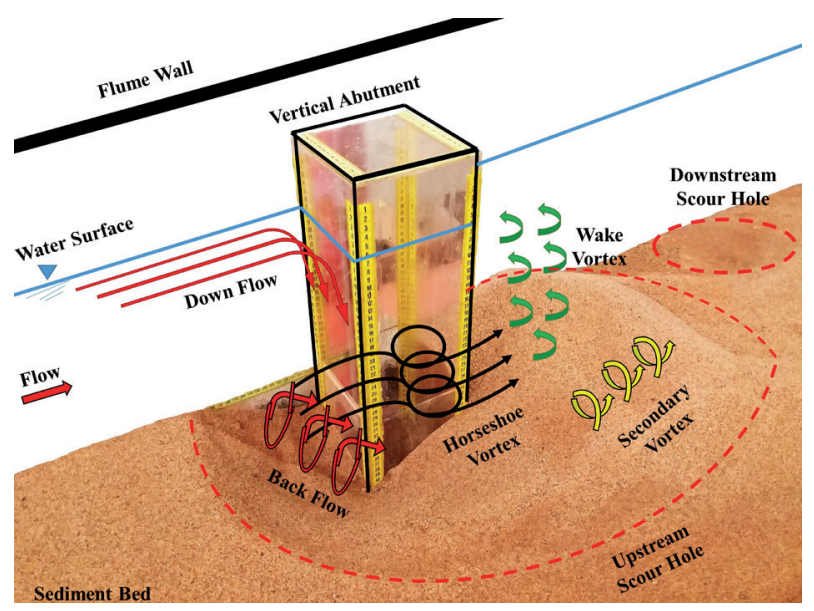

Fig. 1 A schematic figure from flow and vortices around the abutment around the bridge abutment. Indirect methods protect the bridge abutment and the river bank from scouring and eroding by changing the flow velocity algorithm and diverting the flow toward the river centerline.

A spur dike is a type of hydraulic structure that is usually built perpendicular to the river wall in order to protect it, when the river wall is constructed with loose materials, or to prevent eroding of river banks along bends. This structure is also built in the vicinity of other hydraulic structures like bridge abutments to protect them from local scouring and destruction. Spur dikes are usually used in a group form, with the geometric dimensions like their lengths, distances, and installation angles being dominant contributing parameters to their performance efficiency.

Due to the similarity of the scouring mechanism at the bridge abutment and the closed or non-permeable spur dike, the combination of these two structures together creates a rotational flow pattern that leads to sedimentation between them. Thus, by constructing a single spur dike upstream of the bridge abutment, scouring is reduced or eliminated, and sedimentation between them makes the bridge abutment and the riverbank more stable. These protective structures are very easy to construct and economical, considering their remarkable performance in protecting other structures and riverbanks from destruction Li et al. [15]. They studied the performance efficiency of a single spur dike in protecting an abutment against scouring using a series of experiments carried out in a rectangular flume with $30 \mathrm{~m}$ length, $1.2 \mathrm{~m}$ width, and $0.6 \mathrm{~m}$ depth. They defined some long-time experiments for clear water $\left(U_{*} \leq 0.95 U_{* c},=\right.$ bed shear velocity and critical bed shear velocity, respectively) and live bed $\left(U_{*}>U_{* c}\right)$. They compared the final scouring around the abutment with and without the spur dike and concluded that this structure performed very well in protecting the abutment. Li et al. [15] used two types of spur dikes, namely a solid plate as a closed spur dike and riprap as a permeable spur dike. They found that although the closed spur dike was able to well protect the abutment, scouring at the nose of itself may damage the structure, the abutment, and the river bank. Stone or permeable spur dikes have advantages over the closed or impermeable spur dikes, which makes them preferable over others. In fact, downward flows as well as horseshoe and wake vortices all together produce huge scouring around the nose of impermeable spur dike, and this phenomenon is the main cause for the destruction of structure [16]. For this reason, the use of the impermeable spur dike reduces its economic justification. Therefore, 
it appears that by increasing the spur dike permeability, the amount of scouring is reduced around the structure, and the structure stability increases [17, 18]. Permeable spur dikes are highly suitable for deep rivers with high concentration of suspended sediment due to its performance, low construction cost, and consistency with the environment. Another advantage of permeable spur dikes compared to closed spur dikes is the reduction of water surface elevation of rivers during floods [19]. Surely, increasing permeability more than necessary reduces the spur dike efficiency in controlling the river bank and other structures against scouring [20]. There are many published studies in the literature regarding the performance of permeable and impermeable spur dikes in protecting river walls built with loose materials, river banks along bends, and other major downstream structures against scouring and destruction. Almost all of these studies were carried out under steady flow conditions [21, 22]. In recent decades, researchers have focused on scouring around hydraulic structures for unsteady flow conditions. Studies have shown that the maximum scour hole dimensions under unsteady flow conditions are generally less than the corresponding values for steady flow conditions. Melville and Chiew [23] studied the time scale of local scours at bridge piers and showed that $50-80 \%$ of the final maximum scour depth occurred within the first $10 \%$ of the equilibrium time. This implies that for a flood taking about $10 \%$ of the equilibrium time, the maximum scour depth produced by the flood is less (by $20-50 \%$ ) than what occurs under steady conditions. The amount of scouring and eroding under unsteady flow conditions depends on not only sediment specifications and channel geometry, but also flood or hydrograph characteristics such as shape, time to peak, peak discharge, and the whole base time. This is because the flow unsteadiness affects other parameters like depth, velocity, and bed shear stress [24]. In recent years, research on sediment transport and flow algorithms under unsteady flows have increasingly grown due to the similarity of this type of flow with natural conditions in rivers [for example, 25-30].

As it was reviewed, no research has been so far conducted on how to protect the bridge abutment from scouring in unsteady flow conditions. This study aimed to experimentally investigate the effect of a single spur dike with different permeability installed upstream of an abutment to protect it from scouring against hydrographs (i.e., unsteady flow) with different characteristics and to compare the performance of steady and unsteady flow conditions on the abutment protection process.

\section{Materials and methods}

\subsection{Experimental setup}

Experiments were carried out in a water circulating rectangular flume with $10 \mathrm{~m}$ length, $74 \mathrm{~cm}$ width, and $60 \mathrm{~cm}$ depth in the hydraulic laboratory of Shahid Chamran University of Ahvaz, Iran. The walls and bed of the flume were made of glass and steel, respectively. At upstream and downstream of the flume, two tanks were installed and the first one was equipped with a system to reduce water turbulence; thus, the water flow entered into the flume calmly. Discharge was continuously measured using an electromagnetic flow meter with an accuracy of $0.25 \%$ of the measured discharge (e.g., $50.0 \pm 0.125 \mathrm{~L} / \mathrm{s}$ ) and was installed on the entrance pipe of the flume. Two meters of the bed in the middle of the flume were made $20 \mathrm{~cm}$ deeper in a box form and filled by sand with an average diameter $\left(d_{50}\right)$ of $0.7 \mathrm{~mm}$, a specific gravity of 2.65 , and a geometric standard deviation $\left(\sigma_{g}=\sqrt{d_{84} / d_{16}}\right.$, where $d_{84}$ and $d_{16}$ are the diameters with $84 \%$ and $16 \%$ of particles being smaller than them, respectively) of 1.35 . The standard deviation value $(<1.4)$ indicates that the sediment was uniform [31]. This box was far enough (about $3 \mathrm{~m}$ ) from the entrance gate of the flume and therefore, there was not any effect of flow turbulence in this part (see Fig. 2). Many pre-tests were performed to make sure that the length and depth of this box are suitable for this study. Before starting each experiment, the box was filled and levelled in the same manner for all the experiments so that the initial conditions of sediments were the same at the start of each experiment. In order to prevent any creating bed form along with the box and at upstream of the installed structures, water entered into the flume very calmly and after reaching the desired flow depth, the main flow either steady or unsteady was started. A schematic figure from the flume and its apparatus is shown in Fig. 2.

A rectangular piece made of Plexiglas with the dimensions of $14.8 \times 14.8 \mathrm{~cm}$ (length and width, respectively) was used as the bridge abutment and installed perpendicular to the flume wall in the middle part of the moveable bed (sediment box). The abutment length was chosen $20 \%$ of the channel width, i.e., $14.8 \mathrm{~cm}$. This contraction ratio is the maximum recommended value which is usually applied for design of bridge abutments [32]. The abutment was kept non-submerged for the whole hydrograph for all the experiments.

For the experiments with a protective structure, a single non-submerged spur dike was installed perpendicular to the flume wall and at upstream of the abutment to protect 


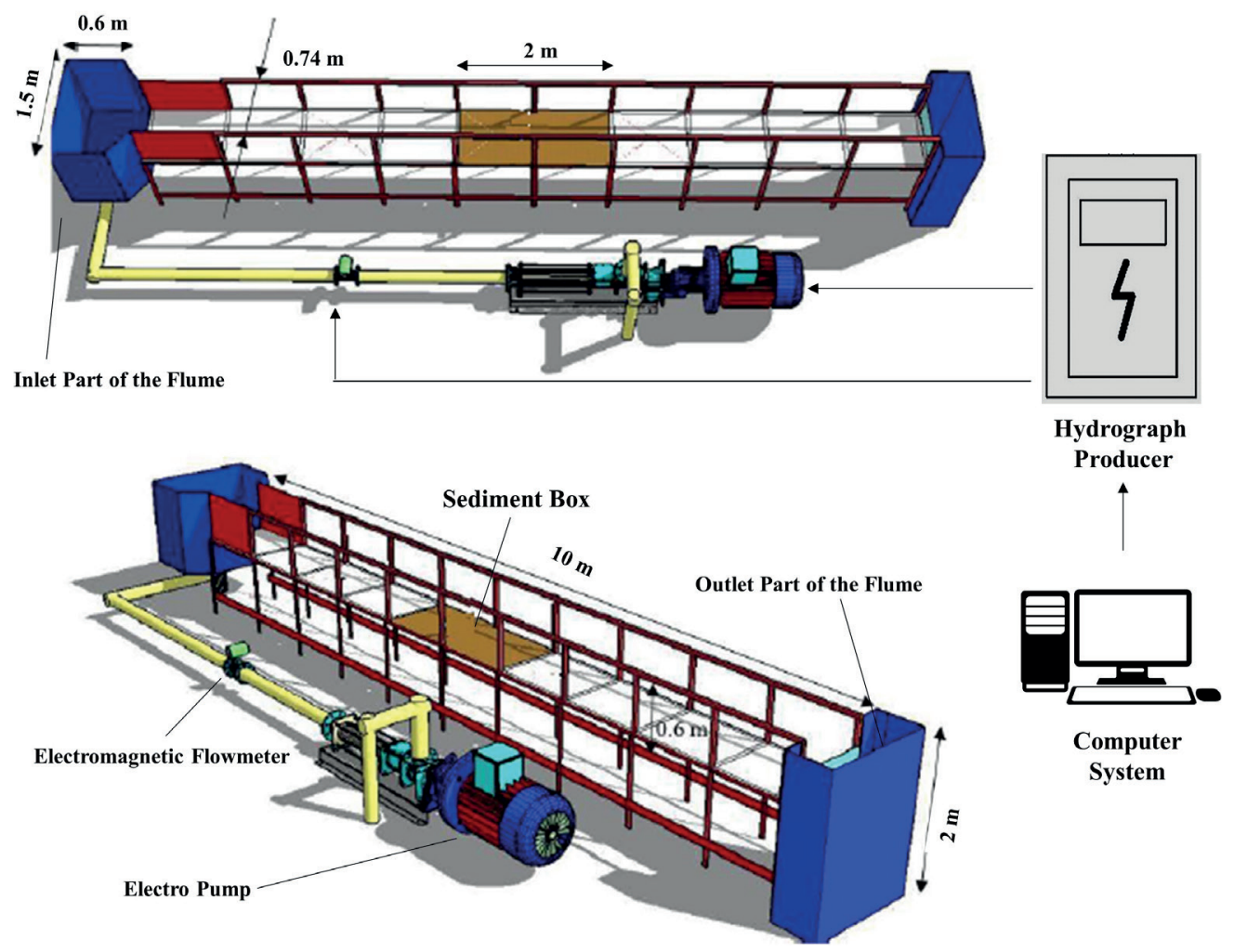

Fig. 2 A schematic figure from the flume and its apparatus

it against local scouring. The permeability percentage $(0 \%$ and $50 \%$ ) of the spur dike and its distance from the abutment (2, 3, and 4 times of the spur dike length) were considered as the geometry variables of the protective structure. The spur dike length was chosen equal to the abutment length, i.e. $14.8 \mathrm{~cm}$. The reason was that it is not economic in real projects with larger values, and for the projects with lower values, the effectiveness of the protective structure may be decreased. The closed spur dike (i.e., 0\% permeability) was made using a small sheet of Plexiglas with dimensions of $14.8 \times 1.0 \mathrm{~cm}$ (length and thickness, respectively). The permeable or open spur dike (i.e., 50\% permeability) was provided using 19 narrow steel wires with a diameter of $4 \mathrm{~mm}$ each and with equal distance from each other $(=4 \mathrm{~mm})$, which were fixed between two narrow Plexiglas straps. Fig. 3 shows two photos from the flume with the installed abutment and the impermeable (Fig. 3(a)) and permeable (Fig. 3(b)) spur dikes. During the experiments, water elevations were measured using a fabric meter attached to the wall of flume far enough $(1.2 \mathrm{~m}$ i.e., 6 times of the maximum depth) at upstream of the structures with an accuracy of $1 \mathrm{~mm}$.

Before starting the main experiments, a relationship between discharge and water elevation $(Q-H)$ was produced with a correlation coefficient of $0.99\left(H=0.418 Q^{0.213}\right.$,

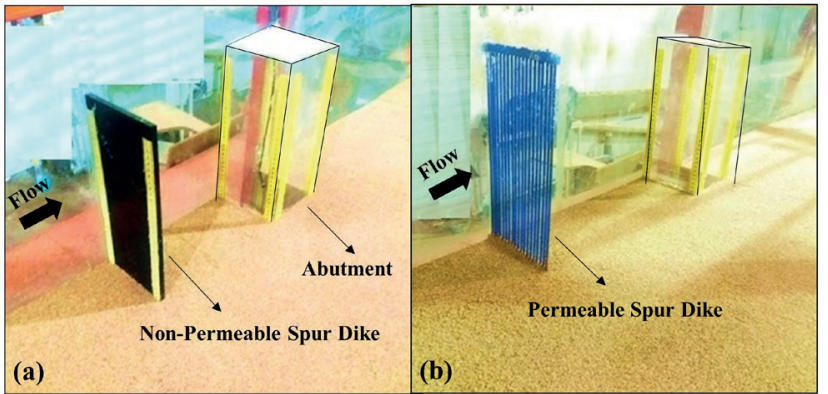

Fig. 3 Photos from the flume and the abutment with a) non-permeable and b) permeable spur dikes

$H$ and $Q$ are in $\mathrm{m}$ and $\mathrm{m}^{3} / \mathrm{s}$, respectively). This relationship was obtained using the measured discharges $(3-60 \mathrm{~L} / \mathrm{s})$ and the corresponding water elevations and applying regression analysis. This equation helped us to convert these two parameters to each other for making sure of the direct measurements during the experiments. It should be mentioned that the sliding gate installed at the end of the flume was fixed all the time and for all experiments.

A well-designed instrument was used to generate an unsteady flow and was combined from two main parts, hardware and software (see Fig. 2). The software part was uploaded and set on a computer, enabling the user to design any type of hydrographs. The hardware contained one electronic part matched with the software and one inverter 
which was able to control and change the pump engine speed and rotation. According to the type of hydrographs for any discharge at any time, the computer software sends a pulse to the electronic part that transmits this command to the inverter. Then, the inverter changes the pump engine speed and discharge. The advantage of this system compared to manual or traditional methods is that we were able to generate a completely continuous unsteady flow.

The maximum scour depth was measured using the fabric meters attached to the structures including abutment and spur dike during the experiments and we were able to record the bed changes with time. To prevent any mistakes for measuring the maximum scour depth due to the light refraction in water, we used a special camera (Digital Borescope QO8 mm-3m Model) underwater and the recorded films were transferred to the computer. The recorded films were then transferred to the Free Video to JPG Converter software package and were converted to several pictures and the maximum scour depth was measured for any desired time using those pictures in the free Graph Grabber software package. Bed topography at the end of each experiment was also obtained using a bed profiler equipped with a laser system and, with an accuracy of $0.1 \mathrm{~mm}$. The laser of this instrument was able to automatically move across the flume ( $y$-direction) and to manually move in the $x$-direction. For any desired accuracy, this device was able to be adjusted in the y-direction. Finally, the collected data ( $x, y$, and $z$ values) were transferred to the supporting computer in an Excel file. In the measuring bed elevations, for the parts near the structures with high fluctuating in bed elevations the mesh size was $1 \mathrm{~cm}$ in the $x$-direction, but in the $y$-direction the instrument automatically recorded 135 points in $60 \mathrm{~cm}$ with an average mesh size of about $4.4 \mathrm{~mm}$ in this direction.

\subsection{Research method and plan}

The experiments were carried out under the both steady and unsteady flow conditions. To ensure clear water conditions, the maximum approach shear velocity $\left(U_{*}\right)$ was kept under $95 \%$ of the critical shear velocity $\left(U_{* c}\right)$ for the threshold movement of the uniform sediment. The peak discharge of all the considered hydrographs was chosen based on the clear water conditions (i.e., $U_{*} \leq U_{* c} 0.95$ ); $56 \mathrm{~L} / \mathrm{s}$ for the flow depth of $23 \mathrm{~cm}$, and the corresponding Froude number of 0.22 . The shear velocity for the threshold movement of the uniform sediment was directly specified using the laboratory observation. It was also double checked using a procedure described by Chow [33]. The base flow discharge or the minimum discharge of the hydrographs was specified in a situation where the abutment was installed in the flume and no movement of sediments around the structure was observed. This discharge value was determined to be equal to $18 \mathrm{~L} / \mathrm{s}$, a flow depth of $17 \mathrm{~cm}$, and a corresponding Froude number of 0.11 .

The hydrograph base time $\left(T_{b}\right)$ and the hydrograph skewness which is usually specified using the time to peak ( $T_{P}$, i.e., the time of hydrograph start to its peak), were the considered hydrograph variables in this study. The three hydrograph base times were 15,30 , and $60 \mathrm{~min}$ and the three skewness values $\left(=T_{P} / T_{b}\right)$ were $0.33,0.5$, and 0.66 . For the skewness value of 0.33 , the slope of increasing discharge is positive for the rising limb of the hydrographs and negative for the recession or falling limb of the hydrographs. However, this is reversed for the skewness value of 0.66 , and the symmetric hydrograph is known with the skewness value of 0.5 .

Therefore, in this research, nine hydrographs were produced and are shown in Fig. 4. In total, 54 experiments were designed and implemented for the unsteady flow conditions. To compare the steady and unsteady flow conditions in terms of local scouring around the abutment and the protective structure (i.e., the spur dike), 18 experiments were also carried out for the steady flow conditions. The discharges for all experiments in steady flow conditions were the peak value of the hydrographs, i.e. $56 \mathrm{~L} / \mathrm{s}$. The plan of all the experiments in this study is summarized in Table 1. To evaluate the performance of the spur dikes in protecting the bridge abutment against scouring, 12 extra experiments were also carried out without the protective structure for the steady and unsteady flow conditions (see Table 1).

Before starting the main experiments, the sliding gate at the end of the flume was adjusted so that for the peak discharge of the hydrographs, the flow depth was equal to $23 \mathrm{~cm}$. For each experiment, first, the bed was levelled, and the flow depth was then adjusted equal to $17 \mathrm{~cm}$ by opening the entrance valve very slowly. At this stage, the discharge was minimum with $18 \mathrm{~L} / \mathrm{s}$. In the next step, in experiments with the steady flow conditions, the flow rate was adjusted for the desired discharge using the entrance valve and the flow meter. For the unsteady experiments, the computer system produced the pre-designed hydrographs. At the end of each experiment after draining of water, bed topography around the structures was measured using the aforementioned laser bed profiler. 


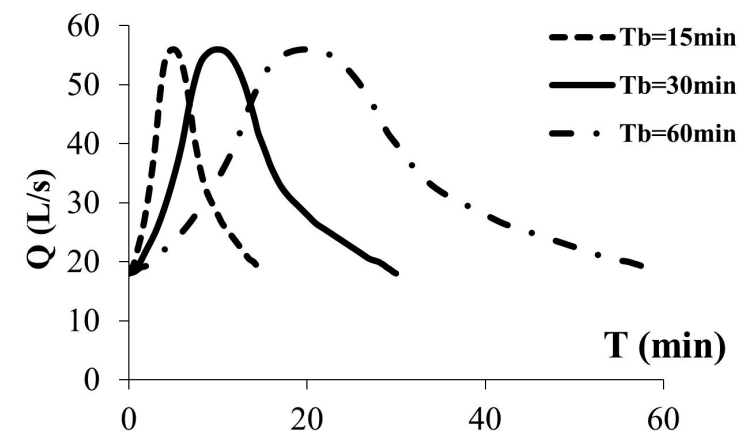

(a)

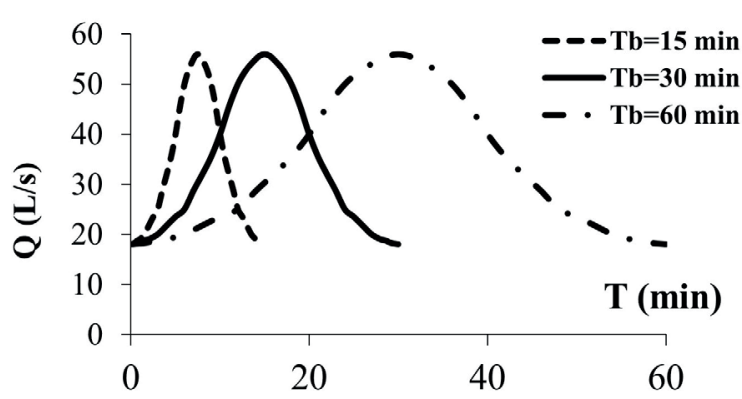

(b)

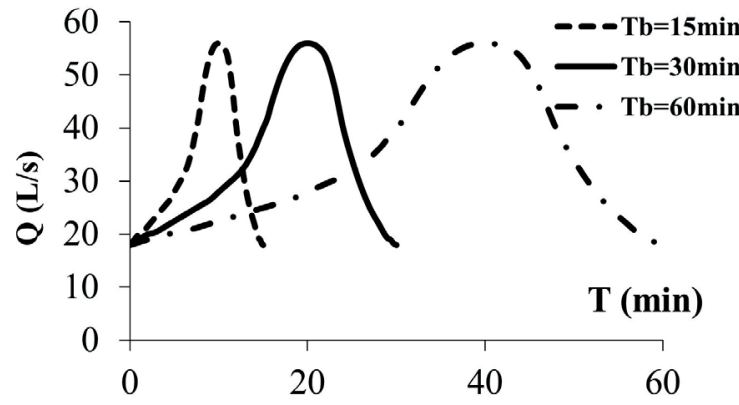

(c)

Fig. 4 Nine types of entrance hydrographs with different skewness, a) left, b) symmetric, and c) right

\section{Results and discussion}

The laboratory observations showed that for all experiments without a protective structure, the local scouring started at the upstream corner of the abutment and the scour hole was extended and became deeper very quickly. During the experiment, sediment from the scour pit wall fell into the pit, and then, due to the presence of vortices and turbulence, the sediment was transferred and accumulated as a sediment dune downstream of the abutment. During this time, the sediment dune moved toward downstream and the scour hole dimensions increased. In this study, the total time of each experiment was not enough to reach the equilibrium size of the scour hole. The maximum scour depth $\left(d_{S}\right.$ in Fig. 5) for all the experiments without spur dike occurred at the upstream nose of the abutment. It seems that the main cause for this phenomenon was the starting point of separation of water from the abutment body, and then, forming of horseshoes, wake vortices, and turbulence. For experiments with the impermeable spur dike, as the protective structure, the scour hole was transferred to the spur dike with the exact same form. This trend of scouring and sedimentation around the structure was almost the same for all the experiments.

\subsection{Abutment scouring without spur dike}

The longitudinal bed profiles at the end of three experiments under the steady flow conditions and nine hydrographs are shown in Figs. 5(a) to 5(c) for the base time of 15,30 , and $60 \mathrm{~min}$, respectively. A photo is added to this figure (Fig. 5(d)), showing the form of scouring around the abutment. In these figures, $\mathrm{L}, \mathrm{S}$, and $\mathrm{R}$ refer to the hydrograph with skewness to the left $\left(T_{P} / T_{b}=0.33\right)$, the symmetric hydrograph $\left(T_{P} / T_{b}=0.50\right)$, and the hydrograph with skewness to the right $\left(T_{P} / T_{b}=0.66\right)$, respectively.

As it is observed from these figures, the maximum scour depth occurred in the vicinity of the upstream corner of the abutment and the washed sediments were left downstream in the form of a sandy dune. Figs. 5(a) to 5(c) show that the longitudinal bed profile at the end of experiments for each of the three hydrographs with the same base time were almost identical. This shows that skewness had not significant effect on the final scour depth. Karimaee Tabarestani and Zarrati [26] obtained the same result for a bridge pier.

Table 1 The plan of all experiments for the steady and unsteady flows

\begin{tabular}{|c|c|c|c|c|c|c|c|c|c|c|c|c|c|}
\hline \multirow{2}{*}{ Conditions } & \multirow{2}{*}{$\begin{array}{l}\text { Protective } \\
\text { Structure }\end{array}$} & \multicolumn{3}{|c|}{$\mathrm{ET}$ or $\mathrm{HBT}^{1}$} & \multicolumn{3}{|c|}{$\mathrm{SV}^{2}$} & \multicolumn{3}{|c|}{$\mathrm{DA}^{3}$} & \multicolumn{2}{|c|}{$\mathrm{PS}^{4}$} & \multirow{2}{*}{$\mathrm{NE}^{5}$} \\
\hline & & 15 & 30 & 60 & 0.33 & 0.50 & 0.66 & 2 & 3 & 4 & $0 \%$ & $50 \%$ & \\
\hline \multirow[t]{2}{*}{ Steady } & $\sqrt{ }$ & $\sqrt{ }$ & $\sqrt{ }$ & $\sqrt{ }$ & - & - & - & $\sqrt{ }$ & $\sqrt{ }$ & $\sqrt{ }$ & $\sqrt{ }$ & $\sqrt{ }$ & 18 \\
\hline & - & $\sqrt{ }$ & $\sqrt{ }$ & $\sqrt{ }$ & - & - & - & - & - & - & - & - & 3 \\
\hline \multirow[t]{2}{*}{ Unsteady } & $\sqrt{ }$ & $\sqrt{ }$ & $\sqrt{ }$ & $\sqrt{ }$ & $\sqrt{ }$ & $\sqrt{ }$ & $\sqrt{ }$ & $\sqrt{ }$ & $\sqrt{ }$ & $\sqrt{ }$ & $\sqrt{ }$ & $\sqrt{ }$ & 54 \\
\hline & - & $\sqrt{ }$ & $\sqrt{ }$ & $\sqrt{ }$ & $\sqrt{ }$ & $\sqrt{ }$ & $\sqrt{ }$ & - & - & - & - & - & 9 \\
\hline Total & - & & - & & & - & & & - & & & & 84 \\
\hline
\end{tabular}

1-Experiment Time (steady) and Hydrograph Base Time (unsteady) min; 2- Skewness Value of hydrographs $\left(T_{P} / T_{b}\right) ; 3$ - Distance from Abutment (=times of the abutment length); 4- Permeability of Spur dike; 5- Number of Experiments 
They mentioned that the bed changing trend with time may be different for different skewness. However, they reported that the final scour depth was independent of the hydrograph skewness.

Comparison of the scour depth between the steady and unsteady flow conditions showed that about $21 \%$ of the maximum scour depth was reduced for the unsteady flow

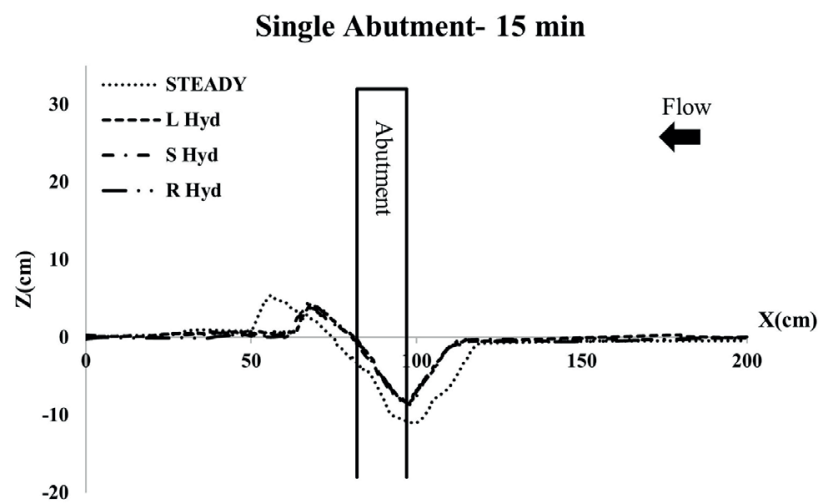

(a)

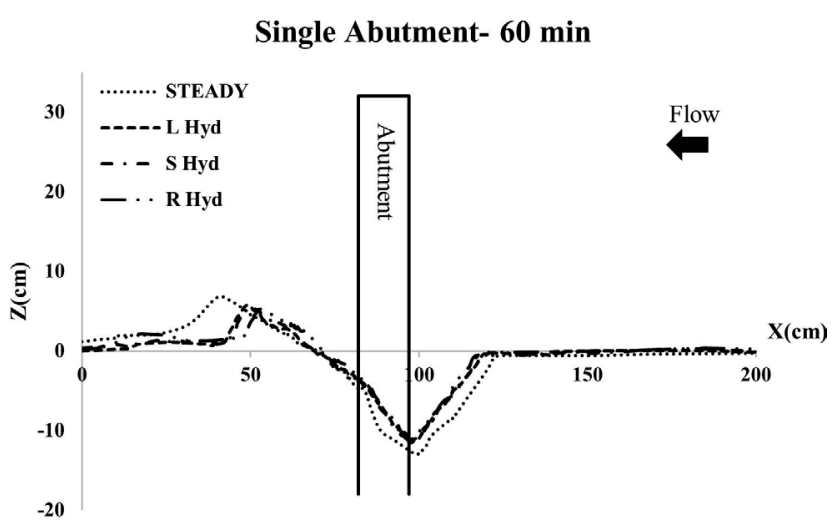

(c) conditions. Fig. 6 illustrates the ratio of the maximum scour depth to the abutment length $\left(d_{S} / L_{a}\right)$ for those 12 experiments. The amount of the reduced maximum scour depths for the hydrographs compared to the steady flow conditions with the similar base time is also shown in this figure. Fig. 6 confirms that the skewness of the hydrographs had not significant effect on the final maximum scour depth.

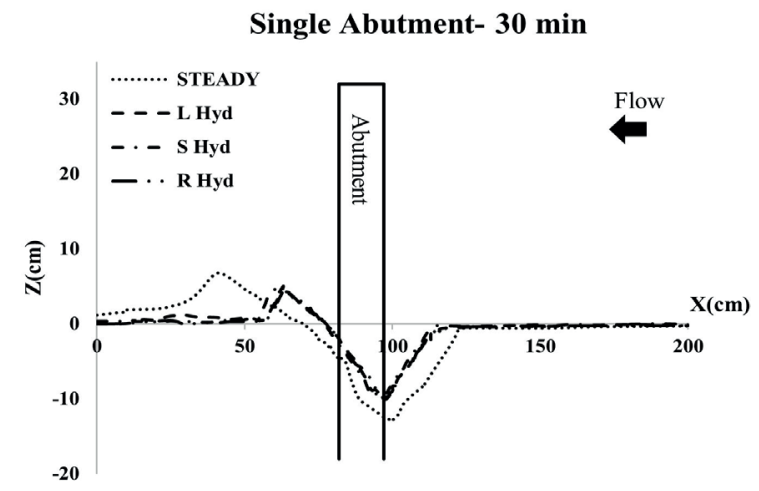

(b)

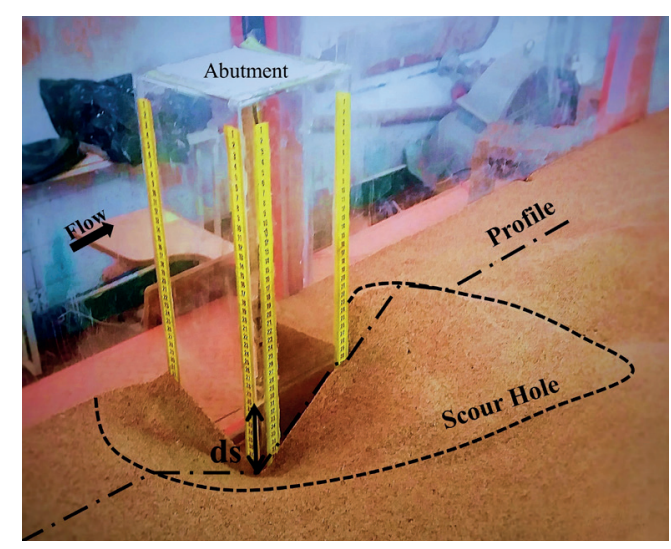

(d)

Fig. 5 The longitudinal bed profile for the steady and unsteady flow conditions at different base time, a) 15 min, b) 30 min, and c) 60 min; d) a photo of the scouring hole around the abutment

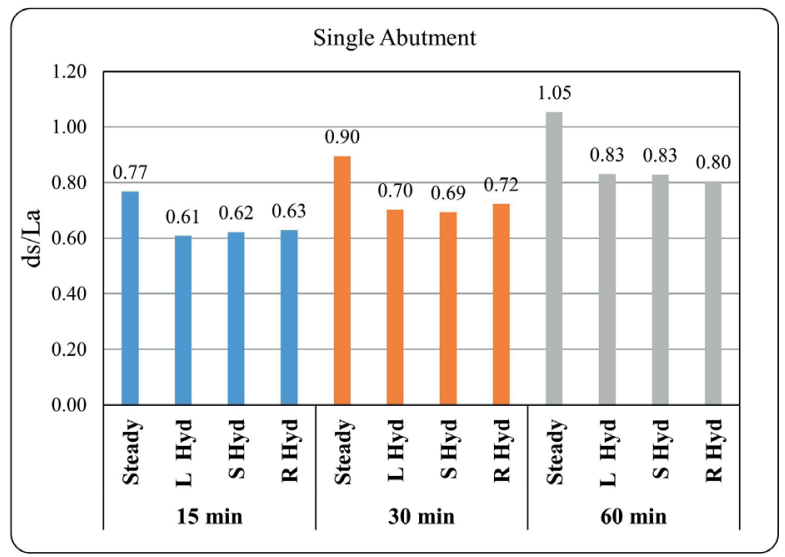

(a)

\begin{tabular}{|c|c|c|}
\hline Type of hydrograph & Time (min) & Reduced percentage (\%) \\
\hline \multirow{3}{*}{ L hydrograph } & 15 & 21 \\
\cline { 2 - 3 } & 30 & 22 \\
\cline { 2 - 3 } & 60 & 22 \\
\hline \multirow{3}{*}{ S hydrograph } & 15 & 19 \\
\cline { 2 - 3 } & 30 & 23 \\
\cline { 2 - 3 } & 60 & 21 \\
\hline \multirow{3}{*}{ R hydrograph } & 15 & 18 \\
\cline { 2 - 3 } & 30 & 19 \\
\cline { 2 - 3 } & 60 & 24 \\
\hline
\end{tabular}

(b)

Fig. 6 (a) The $\left(d_{S} / L_{a}\right)$ values of the abutment without spur dike for the steady and unsteady flow conditions for different base time $\left(T_{b}\right)$ and (b) the reduced percentage of the maximum scour depth for the hydrographs compared to the steady flow conditions 
In average, the maximum scour depth increased by $20 \%$ for the hydrograph base time of $60 \mathrm{~min}$ compared to its base time of $15 \mathrm{~min}$. For steady discharge, the difference between the maximum scour depths for the maximum and minimum times was about $30 \%$.

The stress-time parameter refers to the difference between the maximum scour depths for the steady and unsteady conditions and/or for different flow times. The bed shear stress is defined by $\tau=\gamma R S$, where $\gamma, R$, and $S$ are the specific weight, hydraulic radius, and slope of the energy line, respectively. The slope of the energy line was calculated using the Manning equation [33], with the estimated Manning coefficient of 0.013 .

It is obvious that the bed shear stress would be different for each discharge and/or flow velocity. In this research, the bed shear stresses were calculated as $0.20 \mathrm{~N} / \mathrm{m}^{2}$ and $0.04 \mathrm{~N} / \mathrm{m}^{2}$ for the maximum and minimum discharges, respectively. The bed shear stress-time $(\tau-t)$ parameter expresses the amount of the inserted momentum along the bed per unit area, and its amount may exacerbate the scouring phenomenon. For the maximum discharge, this parameter was calculated as 720 and $180 \mathrm{~N} . \mathrm{s} / \mathrm{m}^{2}$ for the times 60 min and $15 \mathrm{~min}$, respectively. The stress-time parameter is constant and is at its highest value for the steady flow condition; however, it varies for different discharges along each hydrograph. This discussion shows that for each hydrograph the stress-time parameter is gradually increased to its maximum value and it decreases along the recession part of hydrograph. But this parameter is at maximum value for steady flow conditions for all the experiment time, and this is the reason of reduction of scouring around the structures for unsteady in comparison with steady flow conditions.

\subsection{Abutment Protection against scouring by spur dike}

Although the experiment time was not enough for equilibrium conditions, the scour depths were considerable (see Figs. 5 and 6); even for some cases, this value was measured to be more than the abutment length value. This phenomenon may lead to destruction of the bridge abutment and collapse of the bridge. In this study, a spur dike was used at the upstream of the abutment to protect it from scouring. Two types of spur dikes included an impermeable spur dike with zero permeability and a permeable spur dike with $50 \%$ permeability. Figs. 7(a) and 7(b) show the ratio of the maximum scour depth to the abutment length $\left(d_{S} / L_{a}\right)$ at the upstream corner of the abutment for different hydrographs and for the impermeable and permeable spur dikes, respectively. In these figures, $2 \mathrm{~L}, 3 \mathrm{~L}$, and $4 \mathrm{~L}$ represent the

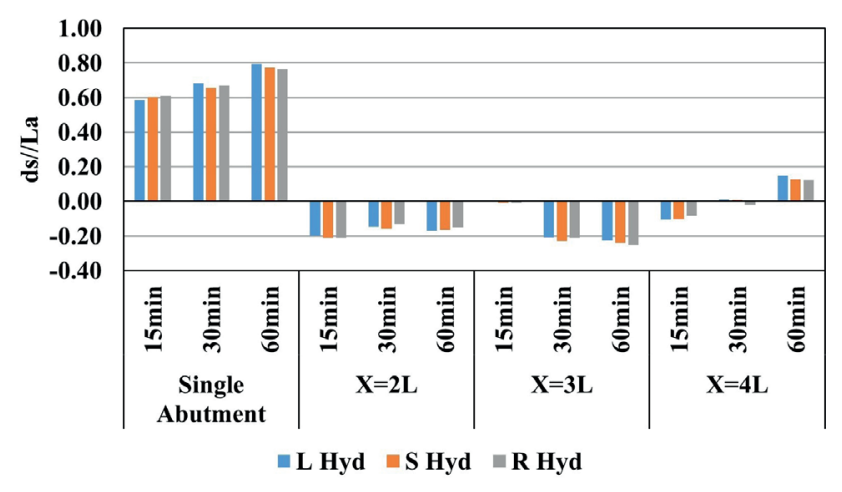

(a)

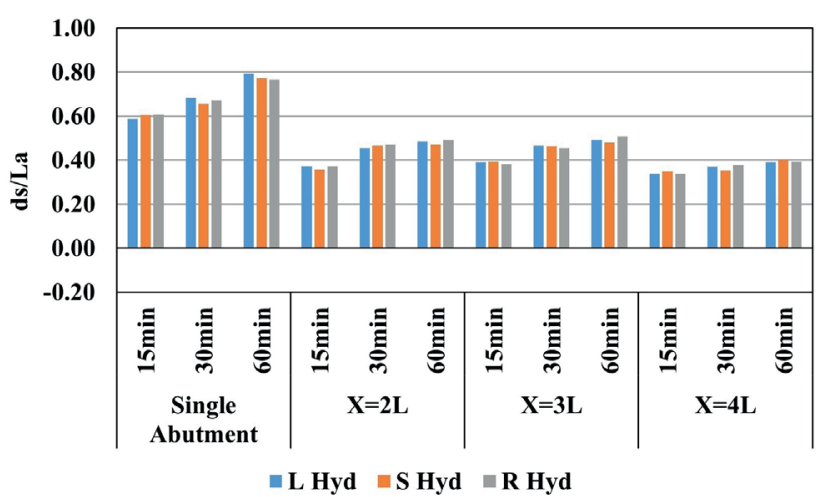

(b)

Fig. 7 The $d_{S} / L_{a}$ values of the abutment for the unsteady flow conditions with a) impermeable and b) permeable spur dikes

distance of the spur place to the abutment, and $\mathrm{L}$ is the abutment length. Since $d_{S}$ is the maximum scour depth, the positive values of this parameter shows the levels lower than the initial horizontal level. Therefore, for negative values sedimentation has happened instead of scouring.

In Fig. 7(a), the negative values of the scour depths show that sediments moved from the spur dike were accumulated around the bridge abutment. In this condition, the stability of the bridge abutment can increase, even more than what was calculated and anticipated during the design program of the bridge. Comparison of the performances of the impermeable and permeable spur dikes in protecting the abutment showed that the closed spur dike was highly successful (see Table 2). As it is observed for the non-permeable spur dike, for almost all the hydrographs and the distances of the spur dikes from the abutment, the sediment dune was formed around the abutment, with the distance of $3 \mathrm{~L}$ being more effective than the other spur dike distances. The permeable spur dike was not able to completely eliminate the scouring process around the abutment. However, the calculation of the measured scour depth at the upstream corner of the bridge abutment with and without the permeable spur dike implies that, on 
average, this structure is able to decrease only about $40 \%$ of scour depths. Table 2 illustrates the protection percentage of the bridge abutment against scouring by the impermeable and permeable spur dikes. The protection percentage is calculated using the following equation and is illustrated in Table 2.

$$
\% P P=\frac{d_{\text {Swithout }}-d_{\text {Swith }}}{d_{\text {Swithout }}} \times 100
$$

Where, $\% P P$ is the protection percentage, $d_{\text {Swithout }}$ and $d_{\text {Swith }}$ are the maximum scour depth without and with spur dike, respectively. It should be noted that all $d_{S}$ (see Fig. 5) values lower than the initial horizontal bed are negative and the values upper than the initial bed (sedimentation instead of scouring) are positive. As it is clear from this table the impermeable spur dike was able to completely eliminate the scouring around the abutment $(P P \%=100 \%)$. In this table for all cases with zero scouring or sedimentation instead scouring the amount of protection percentage is shown with $100 \%$.

The bed topography is shown in Figs. 8(a)-8(c) for a single abutment, an abutment with the impermeable spur dike, and an abutment with the permeable spur dike, respectively. These figures were provided for the hydrographs with the base time of $60 \mathrm{~min}$ and the distance between the spur dike and the abutment of 3L (Figs. 8(b) and 8(c)). Fig. 8(d) illustrates the bed topography for a single abutment and a steady flow with the flow time of 60 min. Comparison of Figs. 8(a) and 8(b) shows that the scour hole was transferred to the protective structure, i.e., the impermeable spur dike, and that the sediment dune was moved toward upstream and around the bridge abutment. Fig. 8(c) shows the performance of the permeable

Table 2 The protection percentage (\%) of abutment against scouring by spur dikes for different hydrographs and distances of the spur dike from

\begin{tabular}{cccccccc}
\multicolumn{4}{c}{ the bridge abutment } \\
\hline & \multicolumn{3}{c}{ Impermeable } & \multicolumn{3}{c}{ Permeable } \\
& $\begin{array}{c}\text { Time } \\
\text { (min) }\end{array}$ & \multicolumn{3}{c}{ Type of Hydrograph } & \multicolumn{3}{c}{ Type of Hydrograph } \\
& & L Hyd & S Hyd & R Hyd & L Hyd & S Hyd & R Hyd \\
\hline \multirow{3}{*}{ 2L } & 15 & 100 & 100 & 100 & 36 & 41 & 39 \\
& 30 & 100 & 100 & 100 & 33 & 29 & 30 \\
& 60 & 100 & 100 & 100 & 39 & 39 & 36 \\
$3 \mathrm{~L}$ & 15 & 99 & 100 & 100 & 34 & 35 & 37 \\
& 30 & 100 & 100 & 100 & 32 & 29 & 32 \\
& 60 & 100 & 100 & 100 & 38 & 38 & 34 \\
& 15 & 100 & 100 & 100 & 42 & 42 & 44 \\
$4 \mathrm{~L}$ & 30 & 98 & 99 & 100 & 46 & 45 & 44 \\
& 60 & 81 & 84 & 84 & 51 & 48 & 49 \\
\hline
\end{tabular}
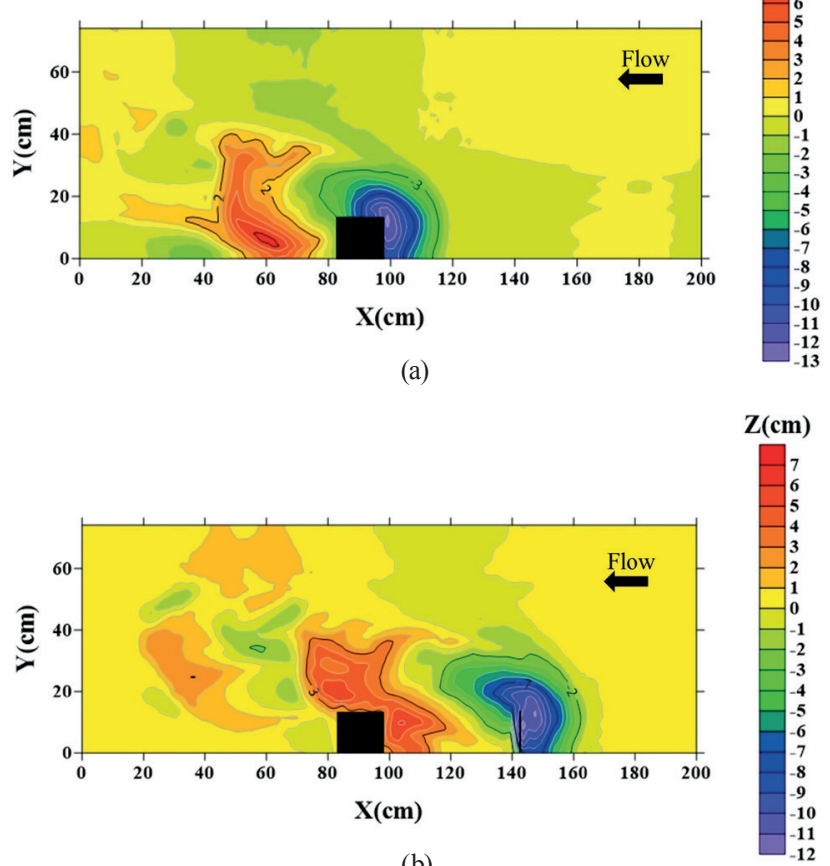

(b)
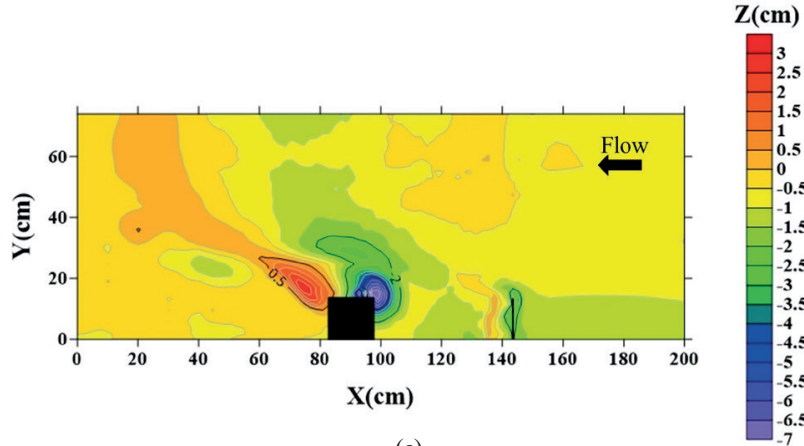

(c)

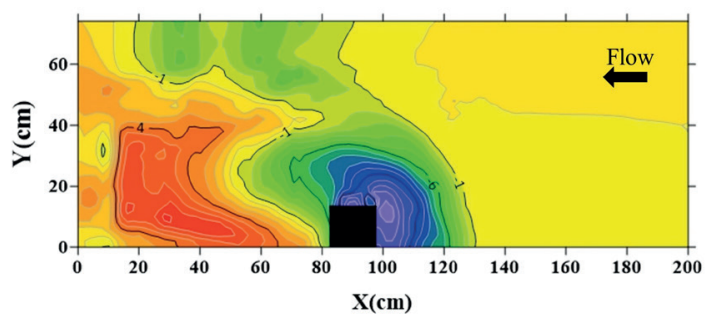

(d)

Fig. 8 The bed topography at the end of experiments for the symmetric hydrographs with the base time of $60 \mathrm{~min}$, a) a single abutment, b) an abutment with the impermeable spur dike, c) an abutment with the permeable spur dike, d) a single abutment for steady flow conditions with the flow time of $60 \mathrm{~min}$

spur dike in protecting the bridge abutment against local scouring. This figure and Table 2 imply that the permeable spur dike was only able to partially control scouring around the bridge abutment. 
Fig. 9 shows the amount of the relative scouring depth for the bridge abutment and the spur dike during a symmetric hydrograph with a peak of $56 \mathrm{~L} / \mathrm{s}$ and a base time of $60 \mathrm{~min}$. In this figure, NPSD and PSD are abbreviations for the non-permeable and permeable spur dikes, respectively. This figure well describes the act of the spur dikes in protecting the bridge abutment against local scouring. It appears that the permeable spur dike works more balanced compared to the impermeable spur dike in terms of receiving protection and preventing scouring around it. Li et al. [15] concluded similar results for the steady flow conditions. Although NPSD was able to completely protect the abutment against scouring, the maximum scour depth at its nose was measured about $78 \%$ of the abutment length.

\subsection{Temporal variations of the maximum scour depth}

Time variations of the maximum scour depth $\left(d_{S}\right)$ measured at the upstream corner of the bridge abutment (see Figs. 5 and 8) was also investigated for all experiments and the results are shown in Fig. 10. In this figure the values are drawn in respect to time for a symmetric hydrograph with and without a protective structure as well as for a single abutment in steady flow conditions with a constant discharge of $56 \mathrm{~L} / \mathrm{s}$. In this figure, the hydrograph has been also appended using the secondary y-axis. The positive values of the relative maximum scour depth show the points under the initial horizontal bed, and negative values vice versa (sedimentation occurred instead erosion). As can be seen from this figure, the relative maximum scour depth becomes almost constant after the hydrograph peak and this is due to decrease of the bed shear stress after its maximum for the maximum discharge.

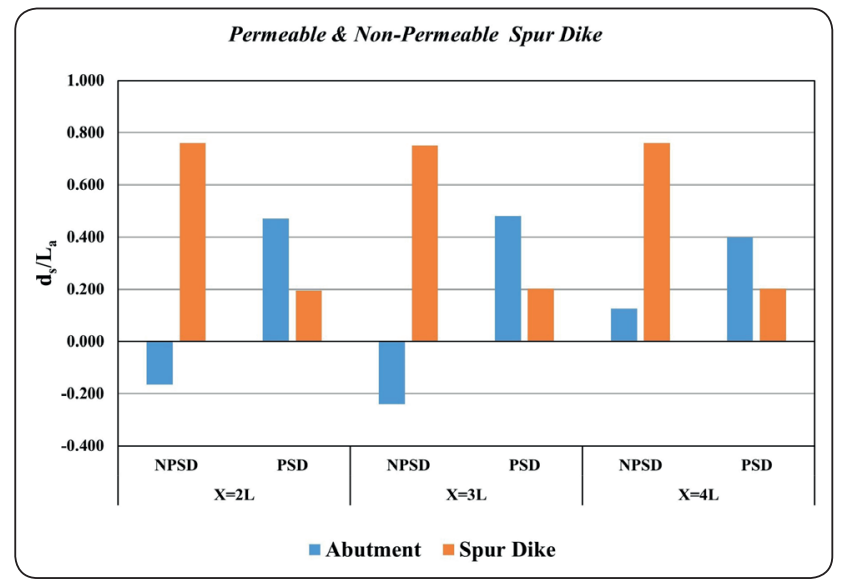

Fig. 9 The relative scouring depth for the bridge abutment and the spur dike (conditions: S Hyd, $T_{b}=60 \mathrm{~min}, \mathrm{NPSD}=$ Non-Permeable Spur Dike, and PSD = Permeable Spur Dike)
Fig. 10 shows that the slope of the curve $\left(d_{S} / L_{a}=f\left(t / T_{b}\right)\right)$ is high (convex arch form) for the steady flow conditions, and this is because the discharge is constant and equal to the maximum value in this study. Therefore, the bed shear stress is at its maximum amount from the starting time of the experiment. For the experiments under symmetric hydrograph with or without protecting structures the slope of the curve is quite different (concave arch form). For the impermeable spur dike as the protective structure, sedimentation occurred instead of erosion at the upstream nose of the abutment.

Although bridge abutments and non-permeable spur dikes have different duties in civil and river engineering, but because of the same shape and structure, the local scouring mechanism around them is the same. Accordingly, both of them occupy a part of the river width and this causes to change the flow pattern around them. If the scour depth at the toe of the hydraulic structure is more than the penetration depth of the structure in the riverbed, the structure will collapse and this causes to destroy the river bank.

Therefore, the depth and volume of the local scouring and factors affecting this process are highly significant. One of the main factors affecting the maximum scour depth and bed topography is the distance between the spur dike and the bridge abutment. This distance should be such that a small and complete but strong vortex is created between the two structures. This vortex settles the washed sediments coming from upstream between the both structures, and this

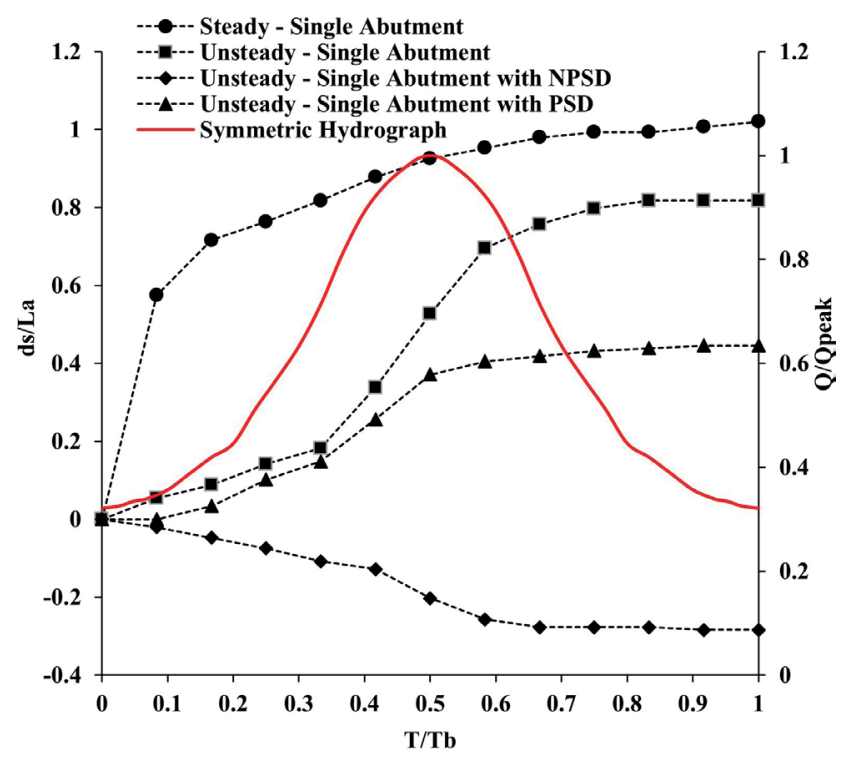

Fig. 10 Temporal variations of relative scour depth at the upstream corner of abutment for different conditions and symmetric hydrograph with base time of 60 min (NPSD: Non-Permeable Spur Dike, PSD: Permeable Spur Dike) 
increases the stability of the river bank and the bridge abutment. If the distance between the spur dike and the bridge abutment increases more than an optimum value, two vortices will be formed in opposite directions and thus they neutralize each other's effects, as shown in Fig. 7(a) and Table 2 (see the difference of the dimensionless scour depth for $3 \mathrm{~L}$ and $4 \mathrm{~L}$ ). If the distance is less than a certain and/or an optimum value, an incomplete vortex will be formed and the created whirlpool cannot settle the washed sediments. According to Table 2, the optimum distance between the non-permeable spur dike and the bridge abutment was two to three times the length of the abutment ( $2 \mathrm{~L}$ to $3 \mathrm{~L}$ ).

A question may be raised here about the stability of the spur dike and the river bank. As it is clear from Fig. 8, the scour hole was extended from the structure nose to the river bank. The mentionable point is that a spur dike is a lightweight structure that can be easily constructed and repaired and its destruction may not cause any serious problem for human life for the short-term. Furthermore, it can be built at a depth of the riverbed clearly greater than the maximum scour depth and also, there are no dead and live loads on these structures. Destruction of the bridge abutment may seriously affect human life by closing the bridge route for weeks, and even months, imposing economic losses, and causing environmental damages. The existence of dead and live loads and inserting of the tractive forces by vehicles make the bridge abutment highly sensitive to any weaknesses and instabilities like local scouring around its base.

Comparison of the performances of permeable and impermeable spur dikes in protecting the bridge abutment against local scouring showed the superiority of the closed spur dike over the open spur dike. However, the stability of the spur dike itself is a major and debatable issue. This issue leads to use of permeable spur dikes instead of non-permeable spur dikes in many river engineering projects. Moreover, permeable spur dikes are consistent with the environment and are easily built at low cost using cylindrical piles made of concrete or iron or bamboo stalks, and even wooden beams. Permeable spur dikes are also highly suitable for deep areas of rivers [19, 21]. Resistance created by this structure against the flow is much lower than that created by the impermeable spur dike. Thus, the scouring area as well as its volume and dimensions around the permeable spur dike are considerably less than what usually occurs for the impermeable spur dike for the same hydraulic conditions or during the similar flood hydrographs (see Fig. 8). For example, the
$d_{S} / L_{a}$ value was about 0.78 at the nose of the impermeable spur dike (Fig. 8(b)) whereas it was measured only about 0.2 for the permeable spur dike (Fig. 8(c)).

Another point that should be mentioned here, all parameters are in the dimensionless form and can be easily converted to the prototype for the river engineering projects.

\section{Conclusions}

This study investigated the effect of closed and open spur dikes on the scour control around the bridge abutment under unsteady flow conditions. Nine hydrographs with two unsteadiness characteristics, i.e., skewness and base time, two types of spur dikes, and three distances of the spur dike from the abutment, in total, 54 experiments were designed and implemented for the unsteady flow conditions. Another 30 experiments were also carried out for the steady flow conditions and for the unsteady flow conditions without protective structures. It was found that the hydrograph skewness did not significantly affect the final scour depth. However, by quadrupling the base time of the hydrograph, only an amount of about $20 \%$ was added to the scour depth. This result shows that most of the sediments around the bridge abutment are washed away during the first minutes of hydrograph crossing. The impermeable spur dike was able to completely eliminate the scouring around the bridge abutment, in special for the distance of $2 \mathrm{~L}$ and $3 \mathrm{~L}$. However, the stability of the impermeable spur dike and the river bank was a big problem due to the transfer of the scour hole to the nose of the spur dike. The permeable spur dike (50\% permeability) was able to only reduce the maximum scour depth around the bridge abutment by an average of $40 \%$, but it acted more balanced in increasing the stability of the bridge abutment and the river bank. The optimal distance between the spur dike and the bridge abutment was found to be two to three times of the abutment length for the unsteady flow conditions. The results showed that, the open spur dike was able to considerably protect the bridge abutment and the river bank against scouring for the unsteady flow conditions. Moreover, there is no serious risk for the local scouring around the permeable spur dike and it can be constructed easily and at low cost. As a result, it is recommended to use this structure for protecting the bridge abutment.

\section{Acknowledgement}

The authors are grateful to Iran National Science Foundation (INSF) and to the Research Council of Shahid Chamran University of Ahvaz for financial support of this study. 


\section{References}

[1] Su, C.-C., Lu, J.-Y. "Measurements and prediction of typhoon-induced short-term general scours in intermittent rivers", Natural Hazards, 66, pp. 671-687, 2013. https://doi.org/10.1007/s11069-012-0509-6

[2] López, G., Teixeira, L., Ortega-Sánchez, M., Simarro, G. "Estimating Final Scour Depth under Clear-Water Flood Waves", Journal of Hydraulic Engineering, 140(3), pp. 725-742, 2014. https://doi.org/10.1061/(ASCE)HY.1943-7900.0000804

[3] Palermo, M., Pagliara, S. "Effect of unsteady flow conditions on scour features at low-head hydraulic structures", Journal of Hydroenvironment Research, 19, pp. 168-178, 2018. https://doi.org/10.1016/j.jher.2017.04.001

[4] Melville, B. W. "Local scour at bridge sites", PhD Thesis, University of Auckland, 1975.

[5] Ettema, R. "Scour at bridge piers", School of Engineering, University of Auckland, Auckland, New Zealand, Rep. 216, 1980.

[6] Wu, P., Balachandar, R., Ramamurthy, A. "Effect of splitter plate on reducing local scour around bridge pier", River Research and Applications, 34(10), pp. 1338-1346, 2018.

https://doi.org/10.1002/rra.3363

[7] Kwan, F. "Study of Abutment Scour", School of Engineering, University of Auckland, Auckland, New Zealand, Rep. 328, 1984.

[8] Kandasamy, J. K. "Abutment scour", School of Engineering, University of Auckland, Auckland, New Zealand, Rep. 458, 1989.

[9] Dongol, D. M. S. "Local scour at bridge abutments", School of Engineering, University of Auckland, New Zealand, Rep. 544, 1994.

[10] Melville, B. W. "Pier and abutment scour: integrated approach", Journal of Hydraulic Engineering, 123(2), pp. 125-136, 1997. https://doi.org/10.1061/(ASCE)0733-9429(1997)123:2(125)

[11] Kothyari, U. C., Garde, R. C. J., Ranga Raju, K. G. "Temporal variation of local scour around circular bridge piers", Journal of Hydraulic Engineering, 118(8), pp. 1091-1106, 1992. https://doi.org/10.1061/(ASCE)0733-9429(1992)118:8(1091)

[12] Dey, S., Barbhuiya, A. K. "Time variation of scour at abutments", Journal of Hydraulic Engineering, 131(1), pp. 11-23, 2005. https://doi.org/10.1061/(ASCE)0733-9429(2005)131:1(11)

[13] Afzalimehr, H., Moradian, M., Singh, V. P. "Flow Field around Semielliptical Abutments", Journal of Hydrologic Engineering 23(2), pp. 571-580, 2018. https://doi.org/10.1061/(ASCE)HE.1943-5584.0001577

[14] Mehta, D. J., Yadav, S. M. "Analysis of scour depth in the case of parallel bridges using HEC-RAS", Water Supply, 20(8), pp. 34193432, 2020. https://doi.org/10.2166/ws.2020.255

[15] Li, H., Barkdoll, B. D., Kuhnle, R., Alonso, C. "Parallel walls as an abutment scour countermeasure", Journal of Hydraulic Engineering 132(5), pp. 510-520, 2006. https://doi.org/10.1061/(ASCE)0733-9429(2006)132:5(510)

[16] Teraguchi, H., Nakagawa, H., Kawaike, K., Baba, Y., Zhang, H. "Effects of hydraulic structures on river morphological processes", International Journal of Sediment Research, 26(3), pp. 283-303, 2011.

https://doi.org/10.1016/S1001-6279(11)60094-2
[17] Pagliara, S., Kurdistani, S. M. "Scour downstream of cross-vane structures", Journal of Hydro-environment Research, 7(4), pp. 236242, 2013.

https://doi.org/10.1016/j.jher.2013.02.002

[18] Pagliara, S., Kurdistani, S. M. "Clear water scour at J-Hook Vanes in channel bends for stream restorations", Ecological Engineering, 83, pp. 386-393, 2015.

https://doi.org/10.1016/j.ecoleng.2015.07.003

[19] Kang, J., Yeo, H., Kim, S., Ji, U. "Permeability effects of single groin on flow characteristics", Journal of Hydraulic Research, 49(6), pp. 728-735, 2011. https://doi.org/10.1080/00221686.2011.614520

[20] Pandey, M., Ahmad, Z., Sharma, P. K. "Scour around impermeable spur dikes: a review", ISH Journal of Hydraulic Engineering, 24(1), pp. $25-44,2017$.

https://doi.org/10.1080/09715010.2017.1342571

[21] Zhang, H., Nakagawa, H. "Characteristics of local flow and bed deformation at impermeable and permeable spur dykes", Annual Journal of Hydraulic Engineering, JSCE, 53, pp. 145-150, 2009.

[22] Mahmoud, M. M., Ahmed, H. S., Abd El-Raheem, G. A., Ali, N. A., Tominaga, A. "Flow analysis around groyne with different permeability in compound channel floodplains", Journal of Engineering Sciences, 41(2), pp. 302-320, 2013. https://doi.org/10.21608/JESAUN.2013.114731

[23] Melville, B. W., Chiew, Y.-M. "Time scale for local scour at bridge piers", Journal of Hydraulic Engineering, 125(1), pp. 59-65, 1999. https://doi.org/10.1061/(ASCE)0733-9429(1999)125:1(59)

[24] Song, T., Graf, W. H. "Velocity and Turbulence Distribution in Unsteady Open-Channel Flows", Journal of Hydraulic Engineering, 122(3), pp. 141-154, 1996. https://doi.org/10.1061/(ASCE)0733-9429(1996)122:3(141)

[25] Lu, J.-Y., Shi, Z.-Z., Hong, J.-H., Lee, J.-J., Raikar, R. V. "Temporal Variation of Scour Depth at Nonuniform Cylindrical Piers", Journal of Hydraulic Engineering, 137(1), pp. 45-56, 2011. https://doi.org/10.1061/(ASCE)HY.1943-7900.0000272

[26] Karimaee Tabarestani, M., Zarrati, A. R. "Local scour calculation around bridge pier during flood event", KSCE Journal of Civil Engineering, 21, pp. 1462-1472, 2017. https://doi.org/10.1007/s12205-016-0986-3

[27] Karimaee Tabarestani, M., Zarrati, A. R. "Local scour depth at a bridge pier protected by a collar in steady and unsteady flow", Proceedings of the Institution of Civil Engineers-Water Management, 172(6), pp. 301-311, 2019. https://doi.org/10.1680/jwama. 18.00061

[28] Salamatian, S. A., Zarrati, A. R. "Reliability study on uncertainty parameters and flood duration on scouring around unprotected and protected bridge piers", ISH Journal of Hydraulic Engineering, 27(Sup1), pp. 11-19, 2019.

https://doi.org/10.1080/09715010.2019.1570360

[29] Gumgum, F., Guney, M. S. "Time Dependent Live-bed Scour Around Circular Piers under Flood Waves", Periodica Polytechnica Civil Engineering, 64(1), pp. 65-72, 2020. https://doi.org/10.3311/PPci.14664 
[30] Link, O., García, M., Pizarro, A., Alcayaga, H., Palma, S. "Local scour and sediment deposition at bridge piers during floods", Journal of Hydraulic Engineering, 146(3), 2020. https://doi.org/10.1061/(ASCE)HY.1943-7900.0001696

[31] Dey, S., Singh, N. P. "Clear-Water Scour Below Underwater Pipelines under Steady Flow", Journal of Hydraulic Engineering, 134(5), pp. 588-600, 2008.

https://doi.org/10.1061/(ASCE)0733-9429(2008)134:5(588)
[32] Barbhuiya, A. K., Dey, S. "Local scour at abutments: A review", Sadhana, 29, pp. 449-476, 2004. https://doi.org/10.1007/BF02703255

[33] Chow, V. T. "Open Channel Hydraulics", McGraw-Hill, New York, NY, USA, 1959. 